DOI: 10.22616/REEP.2019.007

\title{
Professionalism as Viewed by Urban and Rural Teachers in Latvia and Russia: Analysis of Structural Components of Teacher Professional Identity
}

\author{
Jelena Jermolajeva $^{1}$ Dr. paed.; Tatiana Bogdanova ${ }^{2} \mathrm{PhD}$; Svetlana Silchenkova ${ }^{3} \mathrm{PhD}$ \\ University College of Economics and Culture, Latvia ${ }^{1}$ \\ Smolensk State University, Russian Federation ${ }^{2,3}$ \\ jjerm@latnet.lv1,tanbogdan@mail.ru², sil-sv@mail.ru²
}

\begin{abstract}
The present study is a part of the Latvian-Russian research on teacher professional identity. The study is focused on the structural components of teacher professional identity that relate to teachers' understanding of professionalism: Professional Knowledge and Skills, Professional Roles, Professional Attitude to Work. In the international survey carried out in $2017(N=433)$ the questionnaire "Professional Identity of School Teacher" was used. The obtained data were subjected to statistical processing (average score, dispersion, coefficient of variation, mode, Mann-Whitney criterion indicator, Spearman correlation coefficient were calculated). The data of the two samples (Latvian - Russian) and of the four subgroups (urban - rural teachers) were compared. The aim of the article is to study the modern school teachers' understanding of the content of the concept "professionalism" and reveal differences in views and professional intentions of urban and rural teachers from two national samples. The analysis shows that compared with urban colleagues, rural teachers have closer contacts with students and are more involved in the educational process. At the same time, it is more difficult for them to present their achievements and experience to the teaching community; besides, they have problems with research activities. The difference between the national samples in the degree of the involvement in the educational process and interaction with students' families in this process is revealed.
\end{abstract}

Keywords: professionalism, school education, teacher professional identity.

\section{Introduction}

The interrelated concepts of teacher professionalism, teacher professionality, and teacher professional identity are in the focus of many modern pedagogical studies (Hsieh, 2014; Briska, Kaleja-Gasparovica, 2017). The teacher professional identity (TPI) can be considered as the nucleus of professionalism (Voinea, Palasan, 2014; Whitty, 2008). In the last 20 years TPI have been intensively studied in psychological and pedagogical science; now it seems evident that a stable and strong professional identity is the key to success in modern pedagogical work (Olsen, 2016).

TPI is studied in many directions: the essence of TPI is analysed (Bukor, 2011; Mikelsone, Odina, Grigule, 2014); various approaches are proposed to determine the content of TPI (Hsieh, 2014; Medveckis, 2016); the formation and development of TPI is investigated (Vangrieken, Meredith, Kyndt, 2017; Aykac et al., 2017); the interdependence of TPI and work efficiency is examined (Delima, 2015; New Teachers already..., 2015); changes in TPI related to educational reform, which is currently underway in many countries, are traced (Buchanan, 2015). The authors of psychological and pedagogical research agree that TPI implies functional and existential correspondence between person and profession; it includes understanding of the profession, self-acceptance in the profession, and ability to perform the professional duties well. Professional identity is considered as the basis of person's mental development and is characterized by highlighting the following factors: motives for choosing the profession; special features of individual development; features of development of personality as a subject of professional activity; self-assessment of capabilities; system of professional values; awareness of the interaction of the requirements of the profession and personal characteristics.

The content of TPI is the central theme of the international project "Professional Identity of a Modern Teacher", which since 2013 has been carried out by a group of researchers - A. Shpona, M. Vidnere, J. Jermolajeva from Latvia and T.V. Bogdanova, S.V. Silchenkova from Russia (Shpona et al., 2016). In the implementation of the project a six-component structural model of TPI was proposed and a technique was elaborated for its approbation. Being a part of this project, the present study is focused on the three of six structural components of TPI that relate to teacher professionalism: Professional Knowledge and Skills, Professional Roles, and Professional Attitude to Work. These three components are connected with the performance of direct professional duties (first of all work in the classroom and 
appropriate relationship with students). The aim of this article is to study the content of the concept of teacher professionalism as reflected by modern school teachers of Latvia and Russia in relation to the territorial type of the educational environment (an urban or rural school).

\section{Methodology}

In the implementation of the project "Professional Identity of a Modern Teacher" a model of the TPI content was created based on the analysis of scientific sources (Emerson, 2010; Woo, 2013). The model includes six structural components: (1) Philosophy of the Profession, (2) Professional Knowledge and Skills, (3) Professional Roles, (4) Professional Attitude to Work, (5) Cooperation with Colleagues, (6) Professionally Determined Social Behavior (Shpona et al., 2016). In this article the components are considered that are directly related to the meanings the teachers give to the concept of professionalism and the intentions of professional activity resulting from them. These are components 2,3 , and 4 .

To study the model of the content of TPI, the questionnaire "Professional Identity of School Teacher" was elaborated and international survey was carried out in 2017 in a number of schools of Latvia and the Smolensk region of Russian Federation. The sample was created using typical (stratified) repetitionfree method: the general population of school teachers was divided into urban and rural strata, in each stratum the participating schools and individual respondents were randomly selected. Over 20 schools in both national groups participated in the study; the number of the respondents was 437 . The characteristics of samples are shown in the Table 1.

Table 1

Characteristics of Latvian (LV) and Russian (RU) samples of school teachers

\begin{tabular}{|c|c|c|c|c|c|c|c|c|c|c|}
\hline \multirow{3}{*}{$\begin{array}{r}\begin{array}{r}\text { Characte- } \\
\text { ristics }\end{array} \\
\text { Groups }\end{array}$} & \multirow{2}{*}{\multicolumn{2}{|c|}{$\begin{array}{l}\text { Number of } \\
\text { teachers }\end{array}$}} & \multirow{2}{*}{\multicolumn{2}{|c|}{ Age (mean) }} & \multirow{2}{*}{\multicolumn{2}{|c|}{$\begin{array}{c}\text { Work } \\
\text { experience, } \\
\text { years (mean) }\end{array}$}} & \multicolumn{4}{|c|}{ Education (\%) } \\
\hline & & & & & & & \multicolumn{2}{|c|}{ Higher } & \multicolumn{2}{|c|}{$\begin{array}{c}\text { Specialized } \\
\text { secondary }\end{array}$} \\
\hline & $\mathbf{L V}$ & RU & $\mathbf{L V}$ & RU & $\mathbf{L V}$ & RU & $\mathbf{L V}$ & RU & $\mathbf{L V}$ & $\mathbf{R U}$ \\
\hline Urban schools & 182 & 96 & 48.4 & 46.7 & 22.8 & 22.8 & 99.4 & 97.9 & 0.6 & 2.1 \\
\hline Rural schools & 53 & 106 & 47.9 & 46.8 & 22.2 & 26.5 & 100 & 90.6 & 0 & 9.4 \\
\hline All & 235 & 202 & 48.2 & 47.0 & 22.7 & 24.6 & 99.6 & 94.0 & 0.4 & 5.9 \\
\hline
\end{tabular}

To provide the reliability of the study, statistical methods with the significance level of 0.05 were used. The sample errors are $6.8 \%$ in the Russian national sample and $6.4 \%$ in the Latvian one; they are permissible to consider the samples representative for the corresponding general populations. The questionnaire was tested by Cronbach's Alfa method. In the two national groups and four subgroups of respondents (urban/rural schoolteachers), the obtained Cronbach's Alfa coefficients are in the range 0.77 -0.97 , which suffices to recognize the reliability of the technique.

The questionnaire "Professional Identity of School Teacher" consists of 60 statements $(10$ statements in each of the 6 blocks corresponding to 6 components of the TPI model). These statements were offered to respondents to be scored in points from 1 ("strongly disagree") to 6 points ("completely agree"). Some of the statements can be seen in cursive below in the analysis of the corresponding component. In this study, half of the statements of the questionnaire are analysed.

For each item mean rate, dispersion, standard deviation, statistical mode, and coefficient of variation were calculated for the two national samples and the subgroups of urban and rural schoolteachers (the coefficient of variation up to $33 \%$ testifies that the data are reliable and accurate enough to draw conclusions). Using the Mann-Whitney test, statistically significant differences were checked. Within each block and between the blocks, the Spearman rank correlation coefficients were calculated; the statistically significant correlations were analysed.

\section{Results and Discussion}

In this paper three of the six TPI components are considered: Professional Knowledge and Skills, Professional Roles, and Professional Attitude to Work. The general results for the components taken as a whole are shown in Table 2. 
Indicators of $2^{\text {nd }}, 3^{\text {rd }}$, and $4^{\text {th }}$ components of TPI for urban (URB) and rural (RUR) subgroups of Latvian and Russian samples

\begin{tabular}{|c|c|c|c|c|c|c|c|c|}
\hline \multirow[t]{2}{*}{ TPI component } & \multicolumn{2}{|c|}{ Mean value } & \multicolumn{2}{|c|}{ Mode } & \multicolumn{2}{|c|}{ Dispersion } & \multicolumn{2}{|c|}{$\begin{array}{c}\text { Coefficient of } \\
\text { variation } \\
(C o \mathrm{~V}, \%)\end{array}$} \\
\hline & URB & RUR & URB & RUR & URB & RUR & URB & RUR \\
\hline \multicolumn{9}{|l|}{ Latvian sample } \\
\hline $\begin{array}{l}\text { 1. Professional Knowledge and } \\
\text { Skills }\end{array}$ & 4.70 & 4.60 & 5 & 5 & 1.93 & 1.69 & 29.57 & 28.31 \\
\hline 2. Professional Roles & 4.83 & 4.86 & 5 & 6 & 1.41 & 1.43 & 24.61 & 24.58 \\
\hline 3. Professional Attitude to Work & 4.93 & 4.95 & 5 & 5 & 2.03 & 1.13 & 28.92 & 21.50 \\
\hline \multicolumn{9}{|l|}{ Russian sample } \\
\hline $\begin{array}{l}\text { 1. Professional Knowledge and } \\
\text { Skills }\end{array}$ & 4.61 & 4.74 & 5 & 5 & 1.39 & 1.73 & 25.59 & 27.76 \\
\hline 2. Professional Roles & 4.77 & 4.98 & 5 & 6 & 1.15 & 1.43 & 22.46 & 24.01 \\
\hline 3. Professional Attitude to Work & 4.8 & 4.95 & 5 & 6 & 0.96 & 1.41 & 20.45 & 24.03 \\
\hline
\end{tabular}

By the Mann-Whitney U-test, in the TPI components chosen for this article no statistically significant differences were found either between the national samples or between the data of all urban and rural subgroups. However, a detailed analysis of the obtained data makes it possible to find out differences in the reflexive assessment of the certain aspects of professionalism, diversity in attitudes and motives of professional activity between national groups and rural/urban subgroups.

\section{Professional Knowledge and Skills}

A comparative analysis of the data of urban and non-urban schoolteachers of two national samples reveals discrepancies in the assessments of the statements concerning personal contribution of teacher to the development and updating of pedagogical methods and technologies. In the Latvian sample, there are very few teachers who make own professional achievements and ideas known to the pedagogical community. The corresponding statement "I have elaborated innovative educational products that have been approbated, recognized by the professional community, or published in educational journals" has mode 1 ("completely disagree"). Moreover, the answers of the Latvian respondents to this question ate independent of the territorial residence type: mean rates are 3.03 in the urban subgroup and 3.13 and in the rural one; $\mathrm{CoV}$ are $60.08 \%$ and $58.08 \%$, respectively. At the same time, some rural and urban teachers have personal contributions to the improvement of teaching and education methods and would like to make it known to colleagues. The statement "I have a contribution to the improvement of teaching and education methods, but have not been able to let it known to the pedagogical community so far" has the mode indicator 3 and $\mathrm{CoV}=38.46 \%$ for rural schoolteachers, and mode $4, \mathrm{CoV}=44.28 \%$ for urban teachers (the latter give somewhat more affirmative answers to this question than their rural colleagues).

In the subgroups of urban and rural schools of the Smolensk region, the indicators for these items vary significantly. Urban schoolteachers make their pedagogical contributions known to the professional community more often (mode 4, dispersion $2.39, \mathrm{CoV}=44.43 \%$ ) than their rural colleagues (mode 1, dispersion $3.22, \mathrm{CoV}=62.44 \%$ ). At the same time attention is drawn to the fact that, contrary to the Latvian sample, in the Smolensk region the desire to disseminate the own innovative experience is stronger for the rural teachers than for urban ones. It should be noted that in the Russian system for assessment and stimulation of schoolteacher professional activities this is not only a matter of a teacher's personal desire. The status of a teacher and his salary depend on the qualification category obtained in the attestation. According to the instruction developed by the Regional Department of Education, the following requirements are imposed on a teacher for assigning him the high category: “... 4.2. Personal contribution to the improvement of teaching and educational methods (evidence is posted on the Internet resource) ... 4.4 Participation in the work of expert groups, jury of professional competitions. ... 5.1. - 5.4. Dissemination of experience and practical results of professional activities in her/his educational institution, municipality, region, state" (Materialy po attestazii..., 2016). Theoretically, every rural teacher can do it, but in the modern 
Russian society, the opportunities of professional growth of rural teachers are still markedly lower than those of urban teachers. This raises the problem of the professional equality in the Russian teacher community.

\section{Professional Roles}

The greatest difference between national samples is shown in the respondents' answers to the statements: "Studying students' personalities and acquaintance with their family circumstances are no less important than objective assessment of students' success in a subject" and "Teacher is responsible for the education and development of student's personality no less than her/his parents". The Latvian teachers to a lesser extent than the Smolensk colleagues consider the education/upbringing of students as their duty. They are less willing either to take the same responsibility for this as the students' parents (mode 4 versus 5 in the Russian sample), or delve into their personal and family circumstances (mode 5 versus 6 ). It is not clear yet, whether this difference is a result of different national systemic approaches and teaching guidelines, or manifestation of the Latvian national mentality feature of emphasized non-interference in the personal and family circumstances. At the same time, it should be noted that in the answers to the questions from the other structural components of TPI (in particular, the component "Philosophy of the Profession") Latvian teachers show more respect for the student's personality and democratic priorities of the educational process than their Russian colleagues. It can be supposed that for Latvian teachers, the priority of personality implies less pronounced educational/upbringing pressure on student (which is left to family if necessary).

The analysis of the data of urban and rural subgroups revealed an important difference between them. In general, the rural teachers of both countries have closer contacts with students, are more involved in the circumstances of their life, and give higher scores to the own professional role as educator (that is, the person, who not only teaches a subject, but cares for student's well-being and harmonious development as well) than the urban pedagogues. The rural teachers are more often ready to take the same responsibility as parents for this aspect of education (mode 6 versus 5 in the Russian rural and urban subgroups; 5 versus 4 , relatively, in the Latvian sample). In traditional culture, whose features remained to a greater degree in countryside than in cities (due to rural people closer communication and preserved tradition of collective forms of problem solving), teacher is a respected authority in the field of education/upbringing. At the same time, the rural teachers, highly evaluating their pedagogical mission and taking the task of education of students, less often give high scores to the statement "I believe it is right that a teacher simultaneously performs several professional roles". In the Latvian sample, the mode of this item is 4 in rural and 5 in urban subgroup. In each Russian subgroup the mode is 5; however, taking into account the mean rates and $\mathrm{CoV}$, the proportion of teachers' views on this matter seems very similar to the Latvian case. It appears that the rural teachers more than their urban colleagues doubt the possibility to effectively perform all the roles assigned to them by the educational system, first of all the roles of subject teacher and educator. Probably, this indicates that they feel a greater responsibility for the education of students.

The professional role "teacher as researcher" received the least support of the respondents. The statement "I regularly undertake pedagogical research" has minimal values of mode and arithmetic mean among all other items of the block. In the Russian rural subgroup, the mode of this statement is 3 ("rather disagree"), while in other three subgroups it is 4 . Although the mode of this item in the Latvian rural group is the same as in the urban one, other indicators of this issue (mean rate, dispersion and $\mathrm{CoV}$ ) show a similar situation. In the countryside, the roles of subject teacher, educator practitioner, assistant, consultant on the questions of personal development seem more important to the teacher than the roles of observer, theorist, and analyst of the pedagogical process.

\section{Professional Attitude to Work}

The values of mode and mean rates (giving an adequate representation of teachers' views since $C o V$ are not high) show that for the survey participants, honesty and integrity in the performance of work duties is an obligatory quality of pedagogical professionalism; in both national samples the statement "I honestly perform my professional duties" has mode 6 ("completely agree"). Compared to the Russian colleagues, the Latvian schoolteachers are more inclined to consider their profession as a vocation: the statement "The teacher's profession is my vocation" has mode 6 in both Latvian subgroups, whereas in both Russian subgroups it is 5. At the same time, the correlation analysis shows that from the point of view of the Latvian teachers, pedagogical vocation is primarily connected with the ability to establish equal cooperation between teacher and student; for Smolensk teachers, pedagogical vocation is 
primarily connected with organizing the cooperation between school and student's family in the process of training and education. To study these differences in views of Latvian and Russian teachers an additional research is necessary.

The schoolteachers of both countries consider the subject-subject relationship between teacher and students ("I try to make students positively, meaningfully and fruitfully included in the pedagogical process") as well as methodological skills and creative approach to teaching ("I systematically experiment with techniques / methods / technologies / approaches in my work") as important elements of professionalism. At the same time, in all the subgroups of respondents, the mean rates and modes for the subject-subject relationship are higher than those for methodological experimenting: conscious activity of the students in the classroom seems to the teachers more important. The minimal rates for the statement on methodological creativity of teacher were received in the urban subgroup of the Russian sample (mode 4).

Professionals do not restrict their working hours to the time of lessons and preparing to them. They accept the fact that pedagogues have to work much after hours. The mode of the statement "I am aware that in my profession the working day is non-standardized" is 5 in both national samples. The maximum readiness to work after hours is shown by the subgroup of rural teachers of the Smolensk region (mode 6); in small communities of Russian countryside, teacher continues to be a teacher outside school. Communication and cooperation with parents of students in the process of education ("I consider parents of students as colleagues in education students") are also the most accentuated in this subgroup (mode 6); probably this factor influences the lengthening of working hours considerably. In Russian countryside professional teacher is a volunteer assistant and consultant of parents in education of children. In the Latvian national sample there is no difference between the rural and urban subgroups for this item (in the both subgroups the mode is 5); the Latvian teachers (as well as the Russian urban teachers) believe that they should cooperate with parents of students, but at the same time they think that teachers, as well as parents, have their own roles and responsibility, which should not be confused.

Participation in students' life and interest to successes and difficulties of graduates are, in general, included in the teacher's understanding of the professional attitude to work: in the two national samples and all the four subgroups the mode of the statement "I follow the achievements of my students after they finish school" is 5.

\section{Conclusions}

Compared to their urban colleagues, the rural teachers of both countries have closer contact with students; they are more involved in student's life and give more attention to the student's subjectivity in the pedagogical process. In both countries, very few schoolteachers do pedagogical research. The lack of research work is particularly noticeable among rural teachers.

From the point of view of the Latvian teachers, pedagogical vocation is primarily connected with the ability to establish equal cooperation between teacher and student; for Smolensk teachers, pedagogical vocation is primarily connected with organizing the cooperation between school and family in the process of training and education. The Latvian teachers to a lesser extent than the Smolensk colleagues consider the education/upbringing of students as their duty.

Participation in the life of students and interest to successes and difficulties of graduates are included in the modern teacher's understanding of the professionalism. These aspects of the profession are strongly emphasized in all subgroups.

In the Russian sample, the discrepancy between the answers of rural and urban teachers is greater than in the Latvian one. Russian rural teachers from the Smolensk region give markedly higher rates than their urban colleagues to the importance of teacher's role in the development of student's personality, in stimulating students' intellectual growth and creating a basis for their achievements (which is connected with unequal educational opportunities in the urban and rural social environments in Russia). They attach more significance to new theoretical knowledge and modern theories of education (which signals of shortcomings of the in-service teacher training system). The greater dispersion of rural teachers' answers is due to the more difficult working conditions and lower life standards in Russian countryside. 
For rural teachers of the Smolensk region, the problem of unequal opportunities to promote personal pedagogical experience is topical. This inequality hinders the promotion of new ideas and makes it difficult to heighten their qualification category, which results in status and material constraints.

\section{Bibliography}

1. Aykac N., Yildirim K., Altinkurt Y., Marsh M.M. (2017). Understanding the Underlying Factors Affecting the Perception of Pre-Service Teachers' Teacher Identity: A New Instrument to Support Teacher Education. University Bulletin, 6 (1), 67-78.

2. Briska I., Kaleja-Gasparovica D. (2017). Analysis of Barriers for Creative School Culture in Baltic States. In V. Dislere (Ed.), The Proceedings of the International Scientific Conference Rural Environment. Education. Personality (REEP), 10, 50-55. Retrieved from http://lufb.llu.lv/conference/REEP/2017/Latvia-Univ-Agricult-REEP-2017_proceedings-50-55.pdf

3. Buchanan R. (2015). Teacher identity and agency in an era of accountability. Teachers and Teaching, 21

4. Bukor E. (2011). Exploring Teacher identity: Teachers' Transformative Experiences of ReConstructing and Re-Connecting Personal and Professional Selves. Doctoral Thesis. Toronto: The University of Toronto. Retrieved from https://tspace.library.utoronto.ca/bitstream/1807/31700/6/Bukor_Emese_201111_PhD_thesis.pdf

5. Delima V.T. (2015). Professional Identity, Professional Commitment and Teachers' Performance. International Journal of Novel Research in Education and Learning, 2 (4), 1-12.

6. Emerson C.H. (2010). Counselor Professional Identity: Construction and Validation of the Counselor Professional Identity Measure. $\mathrm{PhD}$ thesis. Greensboro: The University of North Carolina. Retrieved from http://libres.uncg.edu/ir/uncg/f/emerson_uncg_0154d_10396.pdf

7. Hsieh B. (2014). The Importance of Orientation: Implications of Professional Identity on Classroom Practice and for Professional Learning. Teachers and Teaching: Theory and Practice, 21 (2), 178-190.

8. Materialy po attestacii uchitelej dlya ustanovleniya kvalifikacionnoj kategorii (Materials on the certification of teachers to establish the qualification category). (2016). Smolensk: GAU DPO SOIRO (in Russian).

9. Medveckis A. (2016). The reflection of pedagogue's identity in the life activities: Theoretical research model. In V. Lubkina (Ed.), The Proceedings of the International Scientific Conference Society, Integration, Education, IV, 80-96. Rezekne: Rezeknes Tehnologiju akademija. Retrieved from http://journals.ru.lv/index.php/SIE/article/view/1552/1753

10. Mikelsone I., Odina I., Grigule L. (2014). Conceptualizing the understanding of professional identity in teacher's career. European Scientific Journal, 1, 238-249. Retrieved from https://eujournal.org/index.php/esj/article/viewFile/4775/4580

11. New Teachers already Demotivated about Teaching at the Start of Their Careers. (2015). London, UK: Association of Teachers and Lecturers. Retrieved from https://www.atl.org.uk/Images/Jan\%2023\%20for\%2027,\%202015\%20-\%20New\%20teachers\%20alr eady $\% 20$ demotovated $\% 20$ about $\% 20$ teaching $\% 20$ at $\% 20$ the $\% 20$ start $\% 20$ of $\% 20$ their $\% 20$ careers.pdf

12. Olsen B. (2016). Teaching for Success: Developing Your Teacher Identity in Today's Classroom. London, New York: Routledge.

13. Shpona A. (Ed.), Senchenkov N.P. (Ed.), Vidnere M., Ermolaeva E., Bogdanova T., Silchenkova S. (2016). Professionalnaya identichnost pedagoga: sravnitelnoe mezhdunarodnoe issledovanie (Teacher Professional Identity: A Comparative International Study). Smolensk: Izd-vo SmolGU (in Russian).

14. Vangrieken K., Meredith C., Kyndt E. (2017). Teacher communities as a context for professional development: A systematic review. Teaching and Teacher Education, 61, 47-59. Retrieved from https://www.researchgate.net/publication/309134253_Teacher_communities_as_a_context_for_profe ssional_development_A_systematic_review

15. Voinea M., Palasan T. (2014). Teachers' professional identity in the 21st century Romania. Procedia: Social and Behavioral Sciences, 128(4), 361-365. Retrieved from https://ac.elscdn.com/S1877042814022630/1-s2.0-S1877042814022630-main.pdf?_tid=9612571a-1848-4f5697bb-58c2a9bc69b1\&acdnat=1551696140_964df92e6c401ab9e51dd4cf9d149b1f

16. Whitty G. (2008). Changing Modes of Teacher Professionalism: Traditional, Managerial, Collaborative and Democratic. In B. Cunningham (Ed.), Exploring Professionalism. London: University of London, Institute of Education, 28-49.

17. Woo H.R. (2013). Instrument construction and initial validation: professional identity scale in counselling (PISC). $\mathrm{PhD}$ thesis. University of Iowa. Retrieved from http://ir.uiowa.edu/etd/2663 